Finisterra, XXXVII, 73, 2002, pp. 133-137

\title{
O ESPÓLIO CIENTÍFICO DO PROFESSOR ORLANDO RIBEIRO
}

\author{
SUZANNE DAVEAU ${ }^{1}$ \\ Maria Joaquina Feijão ${ }^{2}$ \\ Paulo J. S. Barata ${ }^{3}$
}

\section{O LEGADO AO CENTRO DE ESTUDOS GEOGRÁFICOS DE LISBOA}

Quando criou, em 1943, o Centro de Estudos Geográficos (CEG) de Lisboa, Orlando Ribeiro concebeu-o como um instrumento de trabalho aberto a todos os que desejavam realizar investigação em Geografia. As incipientes colecções do Centro foram formadas pela documentação que já tinha reunido e foram enriquecidas, a pouco e pouco, pelo material científico trazido das suas viagens de estudo. O próprio escritório da sua casa era para ele uma espécie de anexo do Centro, tendo sempre considerado que a sua biblioteca pessoal iria um dia integrar a que aí se organizava, pelo que não raras vezes se torna difícil delimitar a fronteira entre ambas. Os investigadores do Centro, ainda pouco numerosos, colaboravam todos para enriquecer o património comum. Assim se constituíram, passo a passo, as ricas fototeca e mapoteca que o Centro de Estudos Geográficos de Lisboa hoje possui.

Em 1965, Orlando Ribeiro encarregou António Miguel Agostinho, funcionário do Centro, de estabelecer o ficheiro dos milhares de livros e folhetos que já então possuía, a fim de facilitar a sua futura inserção na biblioteca do Centro. Em 1973, transmitiu a direcção deste a investigadores mais novos e, em 1983, sentindo a saúde cada vez mais abalada, quis assegurar o destino do seu espólio científico, mediante a redacção de um testamento, no qual esmiuçou os aspectos que lhe pareciam mais importantes. Preocupava-o, na altura, a futura publicação das suas obras manuscritas ou inacabadas. Foi, felizmente, possível cumprir quase completamente esta parte do testamento antes da sua morte, em Novembro de 1997. Graças ao trabalho de um grupo de colaboradores e discípulos,

1 Investigadora do Centro de Estudos Geográficos, Universidade de Lisboa. E-mail: s.daveau@mail.telepac.pt

2 Bibliotecária. Responsável da Área de Cartografia, Biblioteca Nacional. E-mail: estevesfeijao@yahoo.com.br

3 Bibliotecário (Biblioteca Nacional). Arquivista. Chefe de Divisão do Gabinete de Planeamento, Documentação e Formação (GPDF), Inspecção-Geral da Educação. E-mail: paulobarata2002@sapo.pt 
teve assim a satisfação de assistir à publicação, em boas condições, do essencial da sua obra científica.

Orlando Ribeiro enumerou cuidadosamente no seu testamento os diversos constituintes do seu espólio científico: verbetes, cadernos de campo, notas de leitura, inquéritos, livros anotados nas margens ou com folhas intercaladas, fotografias - que constituem uma parte significativa do espólio, pois Orlando Ribeiro encontrava na fotografia «[...] uma forma de também exprimir a dimensão humana do seu pensamento» ${ }^{4}-$, gravuras e mapas, livros, revistas, folhetos de Geografia e Ciências afins, livros ilustrados de interesse geográfico, a sua colecção de bilhetes postais. A que se juntam os retratos, a correspondência, os livros e os artigos recebidos como oferta, os diplomas ou insígnias, e ainda a colecção de candeias, que os alunos lhe davam ritualmente «em lembrança das luzes recebidas nas excursões», reflexos mais pessoais da sua vida científica.

Estima-se que o total do legado seja constituído por cerca de 30.000 documentos de diversos tipos. Uma parte encontra-se já incorporada nas colecções do Centro de Estudos Geográficos de Lisboa e catalogada segundo as normas aí vigentes (sobretudo as fotografias, mapas e revistas, bem como parte dos livros); certo número de duplicados foram dados ao Instituto de Geografia da Faculdade de Letras do Porto, criado em 1973. Importa agora tratar, em primeiro lugar, o material conservado em Vale de Lobos, ou seja, os manuscritos, a correspondência, os retratos, os cadernos de campo (só em parte já repertoriados por lugares e temas), bem como os livros, revistas e artigos em separatas. O facto de a maior parte destes últimos comportar dedicatórias confere-lhes um valor especial: não reflectem apenas os temas científicos que mais preocuparam Orlando Ribeiro e os seus correspondentes mas, também, o tipo de relações científicas e humanas que os ligava.

\section{O PROJECTO PCTI/GEO/40000/2000}

Para cumprir esta parte do testamento, era obviamente necessário arrumar e tratar devidamente o abundante material documental, acumulado por Orlando Ribeiro, desde os anos 30, por ele e por Suzanne Daveau, a partir de 1966. Um detalhado Projecto de Organização, Acesso e Difusão em Suporte Digital do "Legado do Professor Orlando Ribeiro» foi elaborado, em Abril de 1999, pelas bibliotecárias Vera Oliveira e Joaquina Feijão, respectivamente do Instituto Português do Livro e das Bibliotecas e da Biblioteca Nacional, o que permitiu concorrer ao seu financiamento pela Fundação para a Ciência e Tecnologia. Em Junho de 2000, o Projecto PCTI/GEO/40000/2000, Divulgação de Obras Científicas do Professor Orlando Ribeiro, foi aprovado, sendo a instituição proponente a Fundação da Universidade de Lisboa - Centro de Estudos Geográficos, e o

4 Belo, D. (1999) - Orlando Ribeiro: seguido de uma viagem breve à Serra da Estrela. Assírio \& Alvim (Livros de Fotografia, 13), Lisboa. 
investigador responsável o Prof. Jorge Gaspar, director do Centro, mais tarde substituído por Suzanne Daveau.

$\mathrm{Na}$ altura, um dos filhos do Prof. Orlando Ribeiro, Manuel Ramos Ribeiro, tinha já realizado um importante trabalho de arrumação e classificação temática de parte do espólio, em especial dos abundantes folhetos e manuscritos. A catalogação dos livros e folhetos conservados na casa de Vale de Lobos começou em Março de 2001. Colaboram nesta tarefa dois consultores, com formação superior especializada em Ciências Documentais, nas áreas de biblioteca, arquivo e documentação, e ampla experiência no tratamento de diversos tipos de documentos, designadamente, documentação cartográfica, manuscritos, livro antigo e bibliografia corrente, apoiados por um técnico informático, com grande experiência de gestão de bases de dados bibliográficos, uma licenciada em Geografia e uma técnica com formação e experiência na área das Ciências Documentais. Está assim em curso o tratamento documental automatizado dos impressos conservados em Vale de Lobos, a fim de, no prazo de três anos, se produzir um catálogo electrónico, para se inserir num sítio da internet, de modo a colocar o abundante e valioso material documental identificado pela chancela Legado do Professor Orlando Ribeiro, à disposição cómoda de, como foi definido no testamento de 1983, tanto os «colaboradores do Centro de Estudos Geográficos [como as] pessoas interessadas, de qualquer nacionalidade, com a condição de indicarem claramente a proveniência, sempre que o utilizarem nas suas publicações».

Pondera-se ainda, actualmente, o melhor destino final a dar aos documentos que vão sendo tratados. Orlando Ribeiro tinha pensado que o conjunto do seu espólio pudesse ser reunido no gabinete que ocupou, tantos anos, nas instalações do Centro. Mas o espaço é claramente insuficiente para permitir o cumprimento deste desejo. A construção recente de novas e amplas instalações, num anexo da Faculdade de Letras, destinadas em parte à Biblioteca e à Mapoteca do Centro de Estudos Geográficos, irá permitir assegurar a consulta cómoda a grande parte das colecções, quer em livre acesso, quer sob a forma protegida de reservados. Estão neste caso certas categorias de documentos que exigem maior resguardo e condições restritivas de acesso, como sejam os diversos tipos de manuscritos, desde os cadernos de campo e verbetes de leitura até à própria correspondência, para os quais se procura a melhor forma de conservação e de consulta.

\section{O TRATAMENTO DO ESPÓLIO}

O legado do Professor Orlando Ribeiro que integra, para além da sua biblioteca, o seu arquivo pessoal, e o seu espólio científico, é constituído pela documentação e pelos artefactos materiais reunidos ao longo de uma vida dedicada ao estudo e à investigação, constituindo, por isso, uma importante peça do património cultural do país e devendo «[...] ser assumido como parte da reserva 
cultural estratégica que, porventura, nos singulariza enquanto povo, fundamenta e representa o esteio da nossa identidade» 5 .

No CEG e em Vale de Lobos encontra-se sediado meio século de estudo e investigação e se, no primeiro local, a documentação de Orlando Ribeiro já se encontra reunida à documentação do Centro, no segundo ela permanecia em larga medida no estado original em que este a deixara. Impunha-se, antes de mais, sentir o pulsar da documentação, a vivência dos livros através do maior ou menor manuseamento, perceber a natural acumulação sedimentar do conhecimento, antever as ligações estabelecidas com o meio científico através das dedicatórias, mais formais ou mais afectuosas, testemunhos perenes de um universo que vai para além da materialidade lacónica do livro.

Ainda antes do início do tratamento, a fotografia da biblioteca permitiu fixar na película alguma da ambiência da sua biblioteca, o canto dedicado ao velho mestre Leite de Vasconcelos, que ainda hoje se conserva na casa de Vale de Lobos, os locais de trabalho, porque são vários, alguns contíguos aos lugares de descanso, como o quarto da cave, anexo à sala de trabalho de Verão, resguardada da inclemente soalheira da sala do andar principal, preferida no Inverno, quando a luz irrompia pelas amplas vidraças e onde os gatos ainda hoje se espraiam ao sol. Para além da atmosfera, a fotografia do espólio permitiu ainda preservar, antes da sua transferência, o aspecto original da mesma.

Quanto aos livros e às separatas existentes em Vale de Lobos, e que constituem a prioridade do processamento bibliográfico no âmbito deste projecto, decorre em contínuo a sua transferência para as instalações do CEG onde estão a ser tratados, ou seja, cotados (através de uma cota sequencial alfanumérica), catalogados e classificados (utilizando a CDU - Classificação Decimal Universal), e indexados (utilizando a lista de termos em vigor no CEG) por Suzanne Daveau e por Manuel Ramos Ribeiro.

Os registos bibliográficos resultantes deste projecto seguem as normas nacionais e internacionais de descrição dos diversos tipos de documentos, ou seja, a ISBD - International Standart Book Description e as ISBD específicas para cada género de documento. Do ponto de vista informático são igualmente seguidas as normas nacional e internacionalmente aceites, designadamente o formato UNIMARC, através da parametrização BIBLIObase, que tem como suporte o programa $C D S / I S I S$, assegurando-se deste modo uma eventual integração futura dos registos bibliográficos resultantes do projecto na PORbase Base Nacional de Dados Bibliográficos, gerida pela Biblioteca Nacional, e a compatibilização com outras bases internacionais.

Numa primeira fase chegou a considerar-se a edição de um catálogo impresso, o que atendendo à dimensão do espólio teria de estender-se por vários volumes, cujos trabalhos de pré-impressão e impressão, equacionados com a

5 Oliveira, V. e Feijão, J. (1999) - Legado do Professor Orlando Ribeiro: projecto de organização, acesso e difusão da documentação em suporte digital. Lisboa [Texto não publicado, base do projecto PCTI/GEO/40000/2000, apresentado pelo CEG à Fundação para a Ciência e Tecnologia]. 
dimensão da tiragem, tornavam o empreendimento demasiado oneroso e o produto daí resultante de difícil manuseamento. Perante o que começou a ganhar corpo a ideia da edição electrónica, ou seja, da criação de um sítio e disponibilização na internet da base de dados bibliográficos, associada a uma base de dados de imagem. O catálogo electrónico oferece uma inquestionável vantagem pois irá permitir digitalizar as folhas de rosto com dedicatórias, as marcas de posse, as anotações manuscritas patentes nas obras ou insertas em apontamentos avulsos do próprio Orlando Ribeiro.

A disponibilização na internet alarga o público alvo do espólio de Orlando Ribeiro de um grupo restrito de geógrafos, historiadores e bibliófilos nacionais ao mundo heterogéneo que frequenta a internet, o que de algum modo corporiza também o desejo de universalidade inerente às disposições testamentárias e o profundo sentido humanista que caracteriza a obra ímpar do Prof. Orlando Ribeiro.

O sítio, com acesso permanente, contendo a base de dados bibliográficos, ficará fisicamente alojado num servidor sediado no CEG, sendo este a entidade responsável pela gestão e actualização dos respectivos conteúdos. As vantagens de uma publicação deste tipo são a facilidade de actualização, a difusão a um público muito mais vasto e os custos menores em relação à edição em papel.

A elaboração de uma versão impressa do catálogo, realizada a partir da extracção da base contendo os registos bibliográficos e respectivos índices, ou mesmo de um CD-ROM, constituem ainda possibilidades suplementares de divulgação do legado documental de Orlando Ribeiro, a serem estudadas no final do projecto pelas respectivas coordenações técnica e científica.

Embora o projecto não preveja o tratamento dos manuscritos (verbetes, cadernos de campo, notas de leitura, inquéritos, correspondência pessoal e diplomas), bem como dos objectos pessoais a estes ligados, tais como insígnias, etc., os quais detêm quer um interesse científico, quer um interesse histórico e patrimonial, importa assegurar o seu tratamento futuro, de modo a que também para estes se cumpra a vontade de Orlando Ribeiro.

Poderiam aplicar-se ao espólio científico de Orlando Ribeiro, as palavras do próprio, a propósito da obra Portugal, o Mediterrâneo e o Atlântico, quando refere a grata surpresa que constituiu para si ter encontrado o seu livro em bibliotecas particulares de lugares tão distantes, como Québec e Fortaleza: «Assim ele possa continuar a servir a intenção com que o escrevi» ${ }^{6}$.

6 Nótula à 3. ${ }^{\mathrm{a}}$ ed. de Portugal, o Mediterrâneo e o Atlântico, escrita em 1967. 